\section{Paradigma da disseminação local do carcinoma epidermóide da base de língua}

\author{
Francisco S. Amorim Filho ${ }^{1}$, Josias A. Sobrinho ${ }^{1}$, \\ Abrão Rapoport', Antonio S. Fava ${ }^{1}$, Marcos B. \\ Carvalho $^{1}$, Neil F. Novo ${ }^{2}$, Yara Juliano ${ }^{2}$
}

\section{Paradigm of local spreading in squamous cell carcinoma of the base of the tongue}

Resumo / Summary

\author{
Palavras-chave: disseminação, carcinoma \\ epidermóide, base de língua. \\ Key words: spreading, squamous cell
} carcinoma, base of the tongue.
O bjetivo: Analisar o padrão de disseminação local através da delimitação clínica da extensão da lesão primária assim como os subsítios invadidos. Forma de Estudo: Clínico retrospectivo. Material e Método: Foram analisados os prontuários de 290 pacientes com carcinoma epidermóide de base de língua no Departamento de Cirurgia de Cabeça e Pescoço e Otorrinolaringologia do Hospital Heliópolis, Hosphel, São Paulo - Brasil, de 1977 a 2000, sendo estadiados pelo TNM da UICC, e os resultados analisados pelo teste do Quiquadrado para tabelas Z x N (Cochran) para estudo da associação dos sítios e dimensão da neoplasia em relação à invasão da linha média. Resultados: Com predomínio dos homens (8:1) e da $6^{a}$ década de vida (41,0\%), 83,8\% eram etilistas e tabagistas e em 4,7\% os hábitos estavam ausentes. Quanto aos sintomas, odinofagia (37,6\%), linfonodo $(21,7 \%)$ e a média de tempo entre o $1^{\circ}$ sintoma e o diagnóstico de 6 meses (62,0\%). Quanto ao estadiamento, tivemos T1-T2 (18,3\%), T3 $(32,4 \%)$, T4(50,7\%). Quanto à disseminação local, em direção à valécula $(25,3 \%)$, epiglote $(18,7 \%)$, glote $(2,7 \%)$, anteriormente para o v lingual em $(22,4 \%)$ e póstero lateralmente para a prega faringloepiglótica $(6,6 \%)$ e seio piriforme $(2,2 \%)$. Quanto a ultrapassagem da linha média, isso ocorreu em 66,2\% dos casos, sendo $42,2 \%$ (T2), 54,2\% (T3) e 82,9\% (T4). Conclusão: o carcinoma epidermóide no estádio T4 ultrapassa a linha média da base da língua em 82,9\%.

\begin{abstract}
im: To analyse the local spreading pattern through clinical delimitation of primary lesion extension as well as subsites involvement. Study Design: Chart review. Material and Method: Files of 290 patients with squamous cell carcinoma (SCC) of the base of the tongue from Department of Head Neck and Surgery and Otorhinolaryngology of Hospital Heliópolis, Hosphel, São Paulo, Brazil from 1977 to 2000, were analysed. They were staged through TNM from UICC, and then through thoygh $\mathrm{K}$ square text with $\mathrm{Z} \times \mathrm{N}$ (Cochran) tables for assessment of sites and size association of neoplasia in relation of medium line invasion. Results: Male predominance $(8: 1)$ in $6^{\text {th }}$ decade $(41,0 \%), 83,8 \%$ were alcohol and tobacco dependent and $4,7 \%$ without this habbit. About symptoms, odinophagia $(37,6 \%)$, lymphonode $(21,7 \%)$ and medium time between tho first sympton and diagnosis of 6 months $62,0 \%$ ). About staging, T1-T2 (18,3\%), T3 (32,4\%), T4(50,7\%). Concerning local spreading: valecula $(25,3 \%)$, epiglotis $(18,7 \%)$, glottis $(2,7 \%)$, anteriorly to lingual V $(22,4 \%)$ and postero-lateraly to pharyngoepiglotic fold $(6,6 \%)$, piriform sinus $(2,2 \%)$. About medium line involvement (66,2\%), 42,2\% were (T2), 54,2\% (T3) and 82,9\% (T4). Conclusion: the SCC in T4 stage reach the medium line of base of the tongue in $82,9 \%$.
\end{abstract}

\footnotetext{
${ }^{1}$ Departamento de Cirurgia de Cabeça e Pescoço e Otorrinolaringologia do Hospital Heliópolis, Hosphel, São Paulo. ${ }^{2}$ Departamento de Saúde Coletiva da Faculdade de Medicina da Universidade de Santo Amaro.

Trabalho realizado pelo Departamento de Cirurgia de Cabeça e Pescoço e Otorrinolaringologia do Hospital Heliópolis, Hosphel, São Paulo. Endereço para Correspondência: Prof. Dr. Abrão Rapoport - Rua Iramaia, 136 Jd. Europa 01450-020 São Paulo SP E-mail: arapoport@terra.com.br

Artigo recebido em 06 de fevereiro de 2004. Artigo aceito em 20 de maio de 2004.
} 


\section{INTRODUÇÃO}

Os tumores malignos que acometem a cabeça e pescoço correspondem a 10\% de todos as neoplasias humana, dos quais $40 \%$ estão situados na cavidade oral e orofaringe, sendo a base de língua o segundo sítio mais acometido na orofaringe ${ }^{1}$. Estes tumores são representados em 90 a 95\% dos casos pelo carcinoma epidermóide ${ }^{1-7}$. Acometem com mais freqüência o sexo masculino na $5^{\underline{a}}$ e $6^{\underline{a}}$ décadas de vida $^{8}$, sendo em $80 \%$ atribuído a fatores ambientais, dietéticos, ocupacionais, infecção viral, fator imunológico e alterações genéticas ${ }^{9,10}$. Porém, o fator de risco dominante e comum a quase todos os portadores de câncer de orofaringe continua sendo o consumo de bebida alcoólica em associação ao ta$\operatorname{baco}^{1,7,11-17}$.

O câncer de base de língua cursa silenciosamente, sendo assintomático no início da doença até o crescimento significativo da neoplasia, seguido de odinofagia e dificuldade à deglutição (disfagia) ${ }^{3,718-20}$. A neoplasia da base de língua apresenta-se, freqüentemente, na forma úlcero infiltrativa com o tipo histológico pouco ou moderadamente diferenciado $^{4,21-23}$. Estes tumores se propagam ao longo dos planos de menor resistência pelas estruturas neurovasculares da cabeça e pescoço e pela rica rede de drenagem linfática, podendo invadir outros sítios da orofaringe e estruturas anatômicas adjacentes, com alto índice de disseminação para linfonodos cervicais.

Paralelamente a estas características do tumor, a orofaringe é uma região de difícil acesso e visualização, e muitos dos nossos pacientes e profissionais da área de saúde ignoram a patologia existente neste sítio, resultando em um grande número de casos não diagnosticados no estádio inicial. A conseqüência deste diagnóstico tardio é o alto índice de mortalidade de indivíduos na faixa etária economicamente ativa, tratamentos agressivos e mutilantes, que muitas vezes impossibilitam o paciente de reintegrar-se à família, O presente estudo tem por finalidade analisar o padrão de disseminação local do carcinoma epidermóide da base de língua, por meio da delimitação clínica da extensão da lesão primária assim como os subsítios invadidos.

A partir do conhecimento das rotas de disseminação destes tumores e conseqüente melhor compreensão de sua história natural, será possível a adequação de um plano terapêutico mais apropriado a cada paciente.

\section{MÉTODO}

Foram analisados retrospectivamente os prontuários de 290 pacientes portadores do carcinoma epidermóide da base de língua, diagnosticados no Departamento de Cirurgia de Cabeça e Pescoço e Otorrinolaringologia do Hospital Heliópolis - São Paulo, no período de 1977 a 2000. O critério de inclusão restringia-se a lesões locali- zadas primariamente na base da língua e com resultado histopatológico de carcinoma epidermóide. Todos os pacientes foram examinados através do exame loco-regional completo, com rinoscopia anterior e posterior, oroscopia, laringoscopia indireta, palpação bidigital da base da língua, palpação do pescoço. Procurou-se identificar no exame físico loco-regional as características da lesão primária, topografia, extensão, padrão de crescimento à regiões vizinhas bem como os seus limites (dando ênfase ao fato de ultrapassar ou não a linha média). Os pacientes foram estadiados pelo sistema TNM (UICC 1998) ${ }^{24}$ aceito universalmente para estadiamento do carcinoma epidermóide.

Para análise dos resultados aplicou-se o teste da partição do quiquadrado para tabelas Z x N (Cochran), com o objetivo de se estudar as associações entre os sítios e a dimensão do tumor em relação à invasão da linha média.

\section{RESULTADOS}

Dos 290 pacientes portadores de carcinoma epidermóide de base de língua, encontramos um predomínio dos homens (89,3\%), havendo uma relação de homens e mulheres de 8:1. A doença acometeu os pacientes, predominantemente na $6^{\mathrm{a}}$ década de vida (41\%). A maioria dos nossos pacientes (83.8\%) fumava e bebia, havendo poucos casos (13 pacientes) em que este hábito estava ausente.

Os sintomas iniciais mais freqüentes relatados por nossos pacientes foram dor à deglutição (37.6\%) e caroço no pescoço $(21.7 \%)$, sendo a média de tempo entre o sintoma inicial e o diagnóstico de até 6 meses $(62,0 \%)$.

Quanto à característica macroscópica do tumor, encontramos um maior número de lesão úlcero infiltrativa (76,5\%) seguida do tipo vegetante $(10,3 \%)$.

O grau histológico comum à quase todos os pacientes foi o moderadamente diferenciado $(52,4 \%)$ (Tabela 1$)$. Todos os pacientes foram classificados pelo sistema TNM (UICC, 1998), sendo encontrados 94 pacientes no estádio T3 (32,4\%) e 147 pacientes no estadio T4 (50,7\%) (Tabela 2).

Tabela 1. Pacientes portadores de carcinoma epidermóide de base de língua, segundo o grau histológico da lesão primária.

\begin{tabular}{lcc}
\hline Grau histológico & \multicolumn{2}{c}{ Freqüência } \\
& $\mathrm{N}$ & $\%$ \\
\hline Bem diferenciado & 40 & 13,8 \\
Moderadamente diferenciado & 152 & 52,4 \\
Pouco diferenciado & 28 & 9,6 \\
S.O.E. & 70 & 24,1 \\
\hline Total & $\mathbf{2 9 0}$ & $\mathbf{1 0 0}$ \\
\hline${ }^{*}$ Sem outras especificações & &
\end{tabular}


No nosso estudo houve apenas 4 casos de metástase à distancia, todos para o pulmão. A disseminação do carcinoma epidermóide da base de língua se deu em direção a vários sítios da orofaringe e também para estruturas anatômicas fora deste segmento. A região posterior da orofaringe foi a mais acometida quando comparado aos demais subsítios. O tumor primário cresceu preferencialmente em direção a valécula em 25,3\% dos casos (Figura 1). No sentido oposto, o carcinoma epidermóide da base de língua cresceu em direção a cavidade oral, ultrapassando o "V" lingual e invadindo o corpo da língua em $22,4 \%$ dos casos. (Tabela 3).

Com o crescimento da lesão inicial em direção à valécula, o tumor de base de língua costumeiramente invadia, também, a face lingual da epiglote (18,7\%). Porém, a continuidade desta invasão em direção à sua face laríngea e estojo glótico foi observada em poucos casos (2,7\%) (Figura 2).

Quanto à disseminação para os limites laterais da orofaringe, o carcinoma epidermóide de base de língua invadiu a prega glossotonsilar em 122 casos, sendo a tonsila posteriormente comprometida em 24,4\% (Figura 3).

Em direção à porção pósterolateral da orofaringe,o tumor primário estendeu-se à prega faringoepiglótica em 61 casos e, posteriormente, para o seio piriforme em 26 casos (Figura 4).
Quando analisado o fato da lesão primária ultrapassar ou não a linha média, observamos que o tumor da base da língua em sua maioria $(66,2 \%)$ invadia e a ultrapassava. Quanto ao tamanho do tumor primário (T) e o fato de ultrapassar ou não a linha média, observamos que as lesões em estádio mais avançado (T4) freqüentemente a invadia (Tabela 4). Correlacionando os diferentes sítios invadidos pelo tumor de base de língua, e o fato deste ultrapassar ou não a linha média, observamos que nas distintas regiões a linha média estava invadida pelo tumor primário na maior parte das vezes (Tabela 5). Quanto à lateralidade do tumor não houve diferenças significantes - o lado direito apresentou uma discreta superioridade $(46,2 \%)$.

\section{DISCUSSÃO}

O carcinoma epidermóide de base de língua é considerado uma lesão de crescimento silencioso, assintomático no início da doença, com extensão para outros sítios da orofaringe e até mesmo para fora deste segmento ${ }^{23}$, com alto potencial de infiltração e disseminação cervical uni ou bilateral.

A sintomatologia tardia dos tumores de base de língua deve-se, em parte, à escassa distribuição de fibras sentivas a dor, o paciente, quando apresenta sintomas, já encontra-se com o câncer bastante disseminado ${ }^{25}$. Apresen-

Tabela 2. Pacientes portadores de carcinoma epidermóide de base de língua, segundo o tamanho do tumor e a disseminação regional.

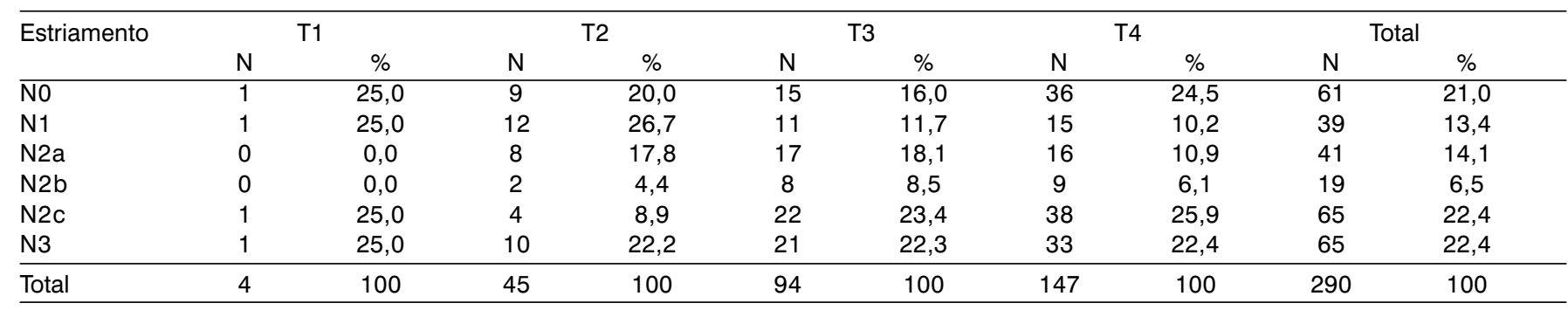

Tabela 3. Pacientes portadores de carcinoma epidermóide de base de língua segundo sua disseminação para outros sítios.

\begin{tabular}{llcc}
\hline Região & Sítio & $\mathrm{N}$ & $\%$ \\
\hline Posterior & Valécula & 235 & 25,3 \\
& Epiglote & 174 & 18,7 \\
\multirow{3}{*}{ Lateral } & Vestíbulo laríngeo & 25 & 2,7 \\
& Prega Glossotonsilar & 122 & 13,1 \\
Anterior & Tonsila & 77 & 8,3 \\
Posterolateral & "V" Lingual/corpo & 209 & 22,4 \\
& Prega farinfoepiglótica & 61 & 6,6 \\
\hline
\end{tabular}




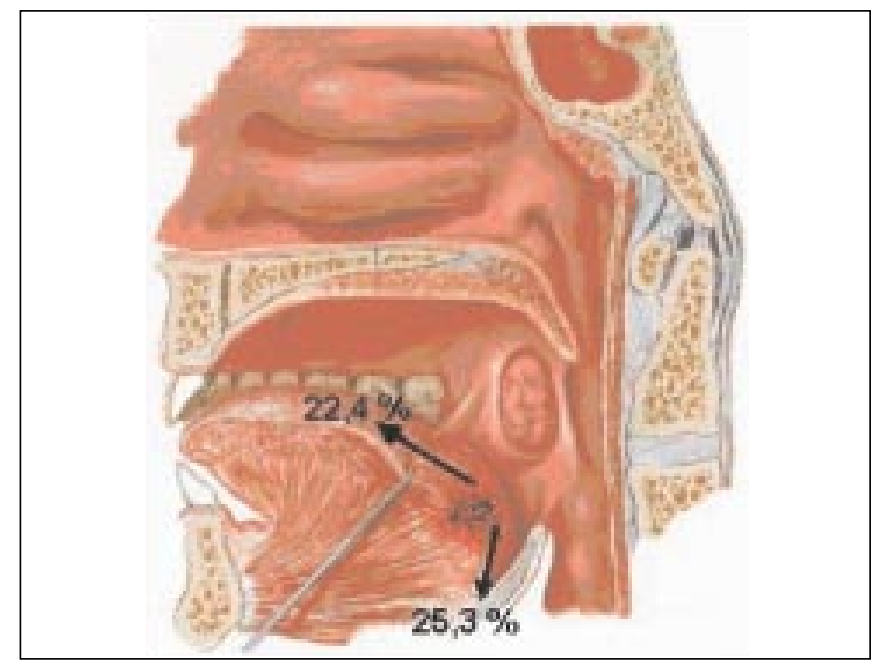

Figura 1. Disseminação do Carcinoma Epidermóide de Base de Língua no sentido Anterior e Posterior.

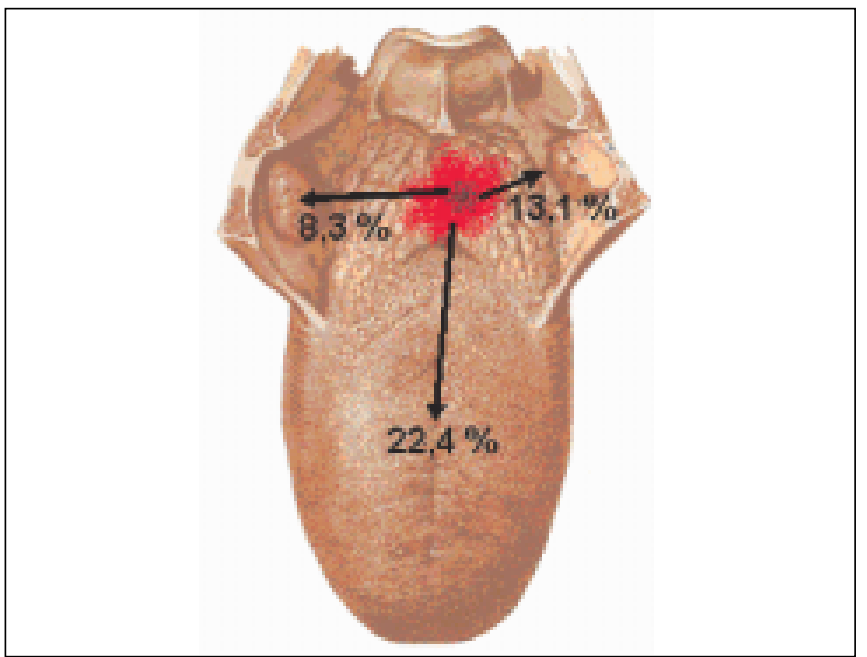

Figura 3. Disseminação do Carcinoma Epidermóide de Base de Língua no sentido anterior e lateral.

ta-se com mais freqüência em estádio avançado no diagnóstico inicial e muitos destes casos, com prognóstico reserva$\mathrm{do}^{26}$.

É de interesse que possamos conhecer quais são os sítios e cadeias linfáticas regionais mais acometidas por esta neoplasia, para melhor adequação de uma tratamento oncológico mais eficaz a estes pacientes.

O sexo masculino é o mais acometido por esta neoplasia, sendo um dos principais fatores que contribuem para alta desproporção entre homens e mulheres, o excessivo consumo de álcool e tabaco no referido gênero. A faixa etária mais acometida está em torno da $6^{\underline{a}}$ década de vida ${ }^{8,23}$. Em nosso estudo a característica macroscópica comum a grande maioria dos portadores de carcinoma epidermóide

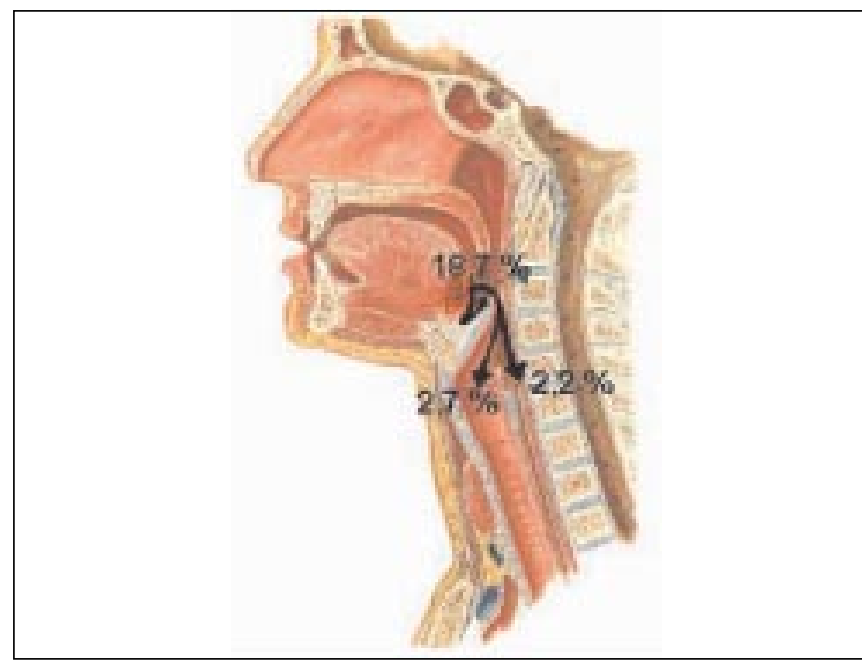

Figura 2. Disseminação do Carcinoma Epidermóide de Base de Língua em direção à Laringe e Hipofaringe.

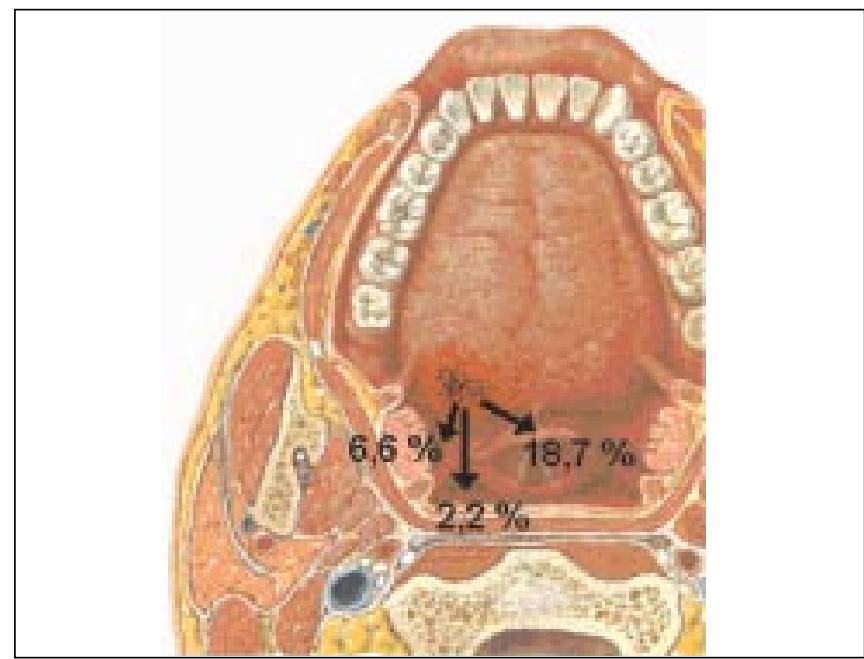

Figura 4. Disseminação do Carcinoma Epidermóide de Base de língua no sentido póstero lateral.

de base de língua é a úlcero-infiltrativa. O comprometimento da sua musculatura pelo tumor, associado ao ato de deglutir alimentos sólidos, assim como a presença de irritantes locais (álcool e fumo) agindo em sua mucosa, geram constantes agressões neste sítio predispondo à ulceração e a dor à deglutição ${ }^{27}$.

O grau histológico mais comum entre os nossos pacientes foi o moderadamente diferenciado. Os carcinomas pouco diferenciados e indiferenciados são mais agressivos, por possuírem uma característica mais infiltrativa, quando comparados aos moderadamente diferenciados e os bem diferenciados ${ }^{3,28}$. A larga maioria dos nossos pacientes apresenta-se com tumores no estádio avançado, T3 (32.4\%) e $\mathrm{T} 4(50.7 \%)^{8,23,29}$. Um dos fatores que contribuem para este 
Tabela 4. Pacientes portadores de Carcinoma Epidermóide da Base de Língua,segundo Tamanho do tumor primátio e a invasão da linha média.

\begin{tabular}{|c|c|c|c|c|}
\hline \multirow[t]{2}{*}{ Estadio } & \multicolumn{2}{|c|}{ Invasão da linha média } & \multirow[t]{2}{*}{ Total } & Proporção de Sim \\
\hline & Sim & Não & & \\
\hline T1 & 0 & 4 & 4 & $0.000000 \rightarrow 0.00 \% \mathrm{~T} 1$ \\
\hline T2 & 19 & 26 & 45 & $0.422222 \rightarrow 42.22 \%$ T2 \\
\hline T4 & 122 & 25 & 147 & $0.829932 \rightarrow 82.99 \% \mathrm{~T} 4$ \\
\hline Total & 192 & 98 & 290 & 0.662069 \\
\hline
\end{tabular}

Qui quadrado

$\mathrm{X} 2=43.922 \mathrm{X} 2=(3 \mathrm{gl} ; 5 \%)=7.815$

Partição do Quiquadrado

$\mathrm{T} 1 \mathrm{Vs} \mathrm{T} 1, \mathrm{~T} 3, \mathrm{~T} 4 \mathrm{X} 2=7.946$

$\mathrm{T} 2, \mathrm{~T} 3 \mathrm{Vs} \mathrm{T} 4 \mathrm{X} 2=34.006$

$(P<0,001)$

Tabela 5. Pacientes portadores de Carcinoma Epidermóide da Base de Língua,segundo sitio acometido e a invasào da linha média.

\begin{tabular}{|c|c|c|c|c|c|}
\hline SITIO & \multicolumn{2}{|c|}{ Invade linha média } & Total & \multicolumn{2}{|c|}{ Proporção de sim } \\
\hline Epiglote & 129 & 45 & 174 & $0.741379 \rightarrow$ & $74.14 \%$ \\
\hline Sulco glossotonsilar & 98 & 24 & 122 & $0.803279 \rightarrow$ & $80.33 \%$ \\
\hline Tonsila & 59 & 18 & 77 & $0.766234 \rightarrow$ & $76.62 \%$ \\
\hline Glote & 21 & '4 & 25 & $0.840000 \rightarrow$ & $84.00 \%$ \\
\hline Total & 714 & 215 & 929 & 0.768568 & $76.86 \%$ \\
\hline
\end{tabular}

Qui quadrado

$X 2=5.250 \mathrm{X} 2=(7 \mathrm{gl} ; 5 \%)=14.067$

$\mathrm{P}=0,5000$

Não significante

elevado índice de casos avançados é a própria localização anatômica da base de língua, que impossibilita a visualização direta desta estrutura de difícil acesso no exame clínico de rotina, e muitas vezes acaba por alojar uma lesão inicial não visualizada pelo profissional de saúde ${ }^{30,31}$. O tamanho do tumor inicial é importante não somente como valor diagnóstico mas também para determinar que procedimento terapêutico poderá ser adotado. O carcinoma epidermóide de base de língua pode progredir em superfície, na submucosa, em várias direções e profundidade, tomando forma infiltrativa com envolvimento precoce da musculatura da língua, em direção aos planos de menor resistência.

No nosso estudo os padrões de disseminação local da lesão primária foram bem documentados; observamos que na maior parte dos casos o tumor cresceu em direção à valécula (25.3\%) com posterior invasão da face lingual da epiglote (18.7\%).

Apenas uma pequena parcela dos tumores que se dirigiam à porção posterior da orofaringe e comprometimento da face laríngea da epiglote invadiam posteriormente o estojo glótico $(2.7 \%)$.
As lesões que crescem em direção à valécula e epiglote podem apresentar com relativa freqüência o comprometimento do espaço pré-epiglótico. A deficiência na definição da invasão deste sitio anatômico que se faz através da valécula em profundidade só pode ser definida no exame tomográfico.

O carcinoma epidermóide de base de língua quando cresce em direção à valécula apresenta maior probabilidade de invadir, também, a face lingual da epiglote do que comprometer outras estruturas anatômicas vizinhas e ate mesmo de permanecer apenas naquele sítio.

A extensão da lesão inicial para a cavidade oral foi observada em $22.4 \%$ dos casos. Nestes casos, o tumor ultrapassou o "V" lingual com posterior invasão do corpo da língua e infiltração da sua musculatura profunda ocasionando redução da sua mobilidade e conseqüente alteração da vOZ do tipo "hot potato voice" ${ }^{2}$.

Quanto ao crescimento lateral, a invasão do prega glossotonsilar ocorreu em $13.1 \%$ dos casos, sendo que em mais da metade destes, também, invadiam a tonsila (8.3\%). A ausência de barreiras naturais entre estas duas estruturas 
favorece a invasão deste sitio da orofaringe. Podemos observar que, estes tumores quando invadem a porção anterior da musculatura da língua, podem também crescer lateralmente envolvendo a tonsila.

Através da palpação bidigital, no comprometimento do sulco glossotonsilar poderá determinar uma possível infiltração precoce da tonsila. Póstero-lateralmente, o carcinoma epidermóide de base de língua estendeu-se à prega faringoepiglótica (6.6\%) e, conseqüentemente, determina invasão do seio piriforme em $2.2 \%$ dos casos. Os tumores de base de língua acometem em uma menor freqüência a hipofaringe e quando o fazem a lesão apresenta-se no estádio avançado com prognóstico reservado, seu crescimento restringe-se na sua maioria aos limites da orofaringe.

A extensão tumoral em direção ao lado oposto à lesão inicial, ultrapassando a linha média da base de língua, ocorreu na maioria dos pacientes em estádio avançado. Porém, quando analisados todos os nossos pacientes segundo o estádio da lesão inicial (T) com a invasão da linha média, observamos que no teste do Quiquadrado houve associação significativa entre o tamanho do tumor primário e a invasão da mesma (linha média). O tumor em estádio mais avançado (T4) apresentou índice de invasão para o lado contralateral em $83 \%$ dos casos.

Com o crescimento lento e progressivo do carcinoma, o mesmo tende a invadir e ultrapassar a linha média com muita freqüência, comprometendo ainda mais a rica rede de drenagem linfática cruzada da língua, disseminando êmbolos tumorais para corrente linfática contralateral, comprometendo os níveis opostos ao da lesão inicial.

Quando analisadas as diferentes regiões anatômicas invadidas pelo tumor de base de língua e o comprometimento da linha média, observamos que no teste do quiquadrado não houve associação significante entre o sítio acometido e a invasão da linha média. Porém, chama-nos atenção para a grande porcentagem da invasão da linha média entre todos os sítios invadidos pelo tumor.

Achamos que o comprometimento da linha média e sua posterior invasão no lado oposto da lesão primária parece ser uma tendência natural do carcinoma epidermóide de base de língua, que acaba por infiltrar precocemente a musculatura contralateral e a rica rede de drenagem linfática cruzada da base de língua.

O carcinoma epidermóide de base de língua é um tumor agressivo que se prevalece da topografia de difícil acesso a propedêutica médica e da escassa fibra sentitiva na região para crescer na obscuridade, invadindo precocemente a musculatura profunda da base de língua e a sua rica rede de drenagem linfática, disseminando células neoplásicas para as cadeias linfáticas do pescoço ${ }^{25}$.

Em decorrência da falta de barreiras naturais na orofaringe, o tumor primário acaba por extender-se sem dificuldade a outros sub-sítios e regiões fora deste segmento.

O exame físico minucioso e a palpação bidigital da base de língua deverá ser procedimento de rotina entre os pacientes acima de 40 anos e com historia de uso de tabaco e álcool em grande quantidade, para o diagnóstico inicial desta neoplasia. Muitas vezes, o exame clínico palpatório é insuficiente para determinar a extensão dos tumores de base de língua, sendo imperativo, em alguns casos, a realização do exame clínico palpatório com o paciente anestesiado, antes de darmos início a qualquer procedimento cirúrgico.

\section{REFERÊNCIAS BIBLIOGRÁFICAS}

1. Kanda JL. Epidemiologia, diagnóstico, patologia e estadiamento dos tumores da faringe. In: Carvalho MB, ed. Tratado de cirurgia de cabeça e pescoço e otorrinolaringologia. São Paulo: Atheneu; 2001.

2. Adamns GL. Cancer of the oropharynx. In: McQuarrie DG, Adamns GL, Shons AR, Browne GA, eds. Head and neck cancer-clinical decisions and management principles. St. Louis: Mosby Year Book; 1986.

3. Kowalski LP, Franco EL, Torloni H, Fava AS, Andrade Sobrinho J, Ramos G, Oliveira BV, Curado MP. Lateness of diagnosis of oral and oropharyngeal carcinoma: factors related to tumor, the patients and helth professionals. Oral Oncol Eur J Câncer 1994; 30:16773

4. Civantos FJ, Goodwin Junior WJ. Cancer of the oropharynx. In: Myers EN, Suen JY, eds. Cancer of the head and neck. Philadelphia: W. B. Saunders; 1996.

5. Plasencia JD, Ramella ET, Ravello JA, Gavidia CG, Abanto WC, Acosta RV. Carcinoma epidermóide de cavidad oral y orofaringe. Diagnostico 1996; 35:14-21.

6. Schantz SP, Harrison LB, Forastiere AA. Oral cavity and oropharyngeal cancer. In: De Vitta JR VT, Hellman S, Rosenberg SA, eds. Cancer: principles and practice of oncology. $5^{\text {th }} \mathrm{ed}$. Philadelphia: Lippincott-Raven; 1997.

7. Seikaly H, Rassekh CH. Oropharyngeal cancer. In: Bailey BJ, Calhoum KH, Deskin RW, Johnson JT, Kohut RF, Pillsbury III HC, Tardy Junior ME. Head and neck surgery: otolaryngology. $2^{\text {nd }} \mathrm{ed}$ Philadelphia: Lippincott-Raven; 1998.

8. Weber PC, Myers EN, Johnson JT. Squamous cell carcinoma of the base of tongue. Eur Arch Otorhinolaryngol 1993; 250:63-8.

9. Day GL, Blot WJ, Austin DF, Bernstein L, Greenberg RS, PrestonMartin S, Schoenberg JB, Winn DM, McLaughlin JK, Fraumeni Junior JF. Racial differences in risk of oral and pharyngeal cancer: alcohol, tobacco and other determinants. J Natl Cancer Inst 1993; 85:465-73.

10. Boffetta P, Merletti F, Magnani C, Terracini B. A population-based study of prognostic factors in oral and oropharyngeal cancer. Oral Oncol Eur J Cancer 1994; 30:369-73.

11. Keller AZ, Terris M. The association of alcohol and tobacco with cancer of the mouth and pharynx. Am J Public Health 1965; 55:1578-85.

12. Rothman K, Keller A. The effect of joint expousure to alcohol and tobacco on risk of cancer of the mouth and pharynx. J Chron Dis 1972; 25:711-6.

13. Rothman KJ, Garfinkel L, Keller AZ, Muir CS, Schottenfeld D. The proportion of cancer attributable to alcohol consumption. Prev Med 1980; 9:174-9.

14. Carvalho MB, Kanda JL, Andrade Sobrinho J, Kowalski LP, Rapoport A, Fava AS, Góis Filho JF, Chagas JFS. Estudo clínico dos tumores malignos da orofaringe. Rev Bras Cir Cab Pesc 1985; 9:13-27.

15. Brugere J, Guenel P, Leclerc A, Rodriguez J. Differential effects of tobacco and alcohol in cancer of the larynx, pharynx and mouth. Cancer 1986; 57:391-5.

16. Blitzer PH. Epidemiology of head and neck cancer. Semin Oncol1988; 15: 2-9. 
17. Franco EL, Kowalski LP, Oliveira BV, Curado MP, Pereira RN, Silva ME, Fava AS, Torloni H. Risk factors for oral cancer in brazil: a case control study. Int J Cancer 1989; 43:992-1000.

18. Tuyns AJ. A etiologj of Head and Neck Cancer: Tobacco, Alcohol and Diet. Adv Otorhinolaryngol 1991; 46:98-106.

19. Carter RL, Pittam MR, Tanner NSB. Pain and dysphagia in patients with squamous carcinomas of the head and neck: the role of perineural spread. J Royal Soc Med 1982; 75:598-606.

20. Dicker A, Harrison LB, Picken CA, Sessions RB, O'Malley BB Oropharyngeal cancer. In: Harrison LB, Sessions RB, Ki Hong, W, eds. Head and neck cancer: a multidisciplinary approach. Philadelphia: Lippincott-Raven; 1999.

21. Barrs DM, DeSanto LW, O'Fallon WM. Squamous cell carcinoma of the tonsil and tongue base region. Arch Otolaryngol 1979; 105: 479-85.

22. Rollo J, Rozenbom CV, Thawley S, Korba A, Ogura J, Perez CA, Powers WE, Bauer WC. Squamous carcinoma of the base of the tongue: a clinicopathologic study of 81 cases. Cancer 1981; 47:333-42.

23. Johansen LV, Grau C, Overgaard J. Squamous Cell Carcinoma of the oropharynx,an analysis of treatment results in 289 consecutive patients. Acta Oncol 2000; 39:985-93.

24. TNM - Classification of Malignant Tumours (UICC). Wiley-Liss, Inc. 1997.
25. Nason RW, Anderson BJ, Gujrathi DS, Abdoh AA, Cooke RC. A retrospective comparison of treatment outcome in the posterior and anterior tongue. Am Jour Surg 1996; 172:665-9.

26. Perlmutter MA, Johnsons JT, Snyderman CH, Cano ER, Myers EN. Functional outcomes after treatment of squamous cell carcinoma of the base of tongue. Arch Otolaryngol Head Neck Surg 2002; 128:887-91.

27. Ruff T, Lenis A, Skinner OD. Carcinoma of the oral cavity and oropharynx. Sur Clin Nort Am 1986; 66:659-71.

28. Shah JP. Patterns of cervical lymph node metastasis from squamous carcinomas of the upper aerodigestive tract. Am J Surg 1990; 160:405-09.

29. Kraus DH, Vastola AP, Huvos AG, Spiro RH. Surgical management of squamous cell carcinoma of the base of tongue. Am J Surg 1993; 166:384-8.

30. Kurtulmaz SY, Erkal HS, Serin M, Elhan AH, Cakmak A. squamous cell carcinoma of the head and neck :descriptive analysis of 1293 cases. The J of Laryngology and Otology 1997; 111:531-5.

31. Amorim Filho FS, Andrade Sobrinho J, Rapoport A, Carvalho MB, Novo NF, Juliano Y. Estudo de variáveis demográficas, ocupacionais e co-carcinogenéticas no carcinoma espinocelular da base de língua nas mulheres. Rev Bras Otorrinolaringol 2003; 69:472-8. 